\title{
Dynamic voltage restorer (DVR) in a complex voltage disturbance compensation
}

\author{
Muhammad Alif Mansor, Muhammad Murtadha Othman, Ismail Musirin, \\ Siti Zaliha Mohammad Noor \\ Faculty of Electrical Engineering, Universiti Teknologi MARA, 40450 Shah Alam, Selangor, Malaysia
}

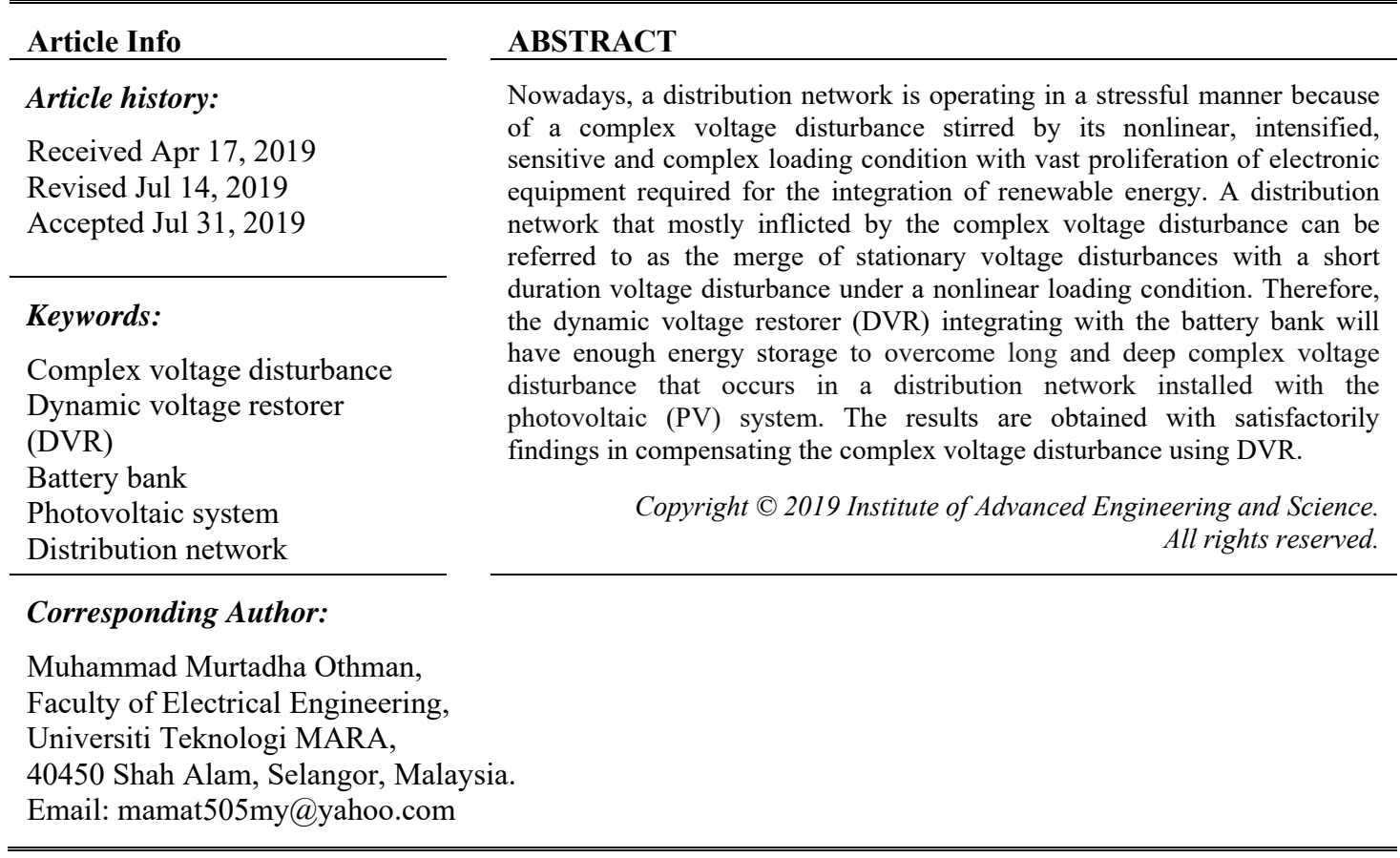

\section{INTRODUCTION}

A complex power quality disturbance that occur in the industrial sectors may cause to a detrimental effect in economic market. Recently, extensive priorities and measures have been given to the industrial sectors utilizing modern automation systems and electronic equipment that will leverage the economic market. This signifies that the industrial sectors constitute with the large number of sensitive and critical loads generally will encounter a negative impact in its system operation due to the increase of complex power quality disturbance and voltage instability arising from the incoming supply system. A complex disturbance in power quality manifested in the voltage, current or frequency may instigate to a breakdown or malfunction of sensitive equipment $[1,2]$. The incoming supply can only control the voltage quality but not for the current drawn by a load. This is the reason that a basic power quality compensation is usually performed by preserving the supply voltage within certain limit. Nevertheless, this not the case that can be resolved for a power quality problem having significant deviation in the voltage magnitude and frequency [3]. The problem becomes heftier due to a vast growth of electronic equipment usage as a nonlinear load inclusive with the renewable energy installed in a distribution network and eventually engender to the power quality problem of complex voltage disturbance.

A power quality problem of complex voltage disturbance event is emanating from the merge of stationary voltage disturbances such as the flicker or waveform distortion with a short duration voltage disturbance such as the sags or transient surges $[4,5]$. In particular, the complex voltage disturbance occur in a distribution network may yield to the voltage sags, under-voltage, voltage swell, over-voltages, voltage harmonic, voltage unbalance, voltage fluctuation or flickers [6]. As a result, this will disrupt the performance of critical or sensitive loads connected at the PCC that are sensitive to the complex voltage disturbance. The 
distorted voltage may result in the end-user equipment to malfunction, overheating, or inefficient yielding to the economic losses [7]. Therefore, it is important for safe and efficient operation of critical or sensitive loads by maintaining a side load voltage in the sinusoidal form. There are various methods used to mitigate the complex voltage disturbances where in the most effective solution is by utilizing the custom power device. To keep sensitive loads from the effects of voltage disturbances at the point of common coupling (PCC), by used the Dynamic voltage restorer (DVR) as a custom power device designed referring to the operating principle of voltage source converter (VSC) [8,9]. A typical location to install the DVR in a distribution network is shown in Figure 1. The fundamental working of DVR is to inject a specific amount of voltage magnitude, frequency and phase angle in series at distribution feeder to compensate the unbalance and distortion while retaining the desired amplitude and waveform of load voltage. However, the capacitor connected at the DC link of VSC is not enough to sustain energy supply into a distribution network. Therefore, the proposed technique of DVR is to integrate with the battery bank at the DC link to provide enough energy to overcome long and deep voltage sag, voltage interruption, and highly voltage unbalance that falls under the complex voltage disturbance. The photovoltaic (PV) system is utilized for the purpose of charging the battery bank in which abundance of green energy can be easily acquired from a free resource [10].

\section{RESEARCH METHODOLOGY}

The DVR is link up in series with the sensitive load in a distribution network as shown in Figure 1. The DVR is operating as the voltage-source converter (VSC) for DC/ AC conversion in which the capacitor is used as the DC voltage source to supply the VSC via DC link followed by the isolation transformer is responsible to inject the series voltage into the distribution line, and eventually, to terminate the switching harmonics of the VSC by used the passive filter. The capacitor connected at the DC link will experience limitation in supplying the energy storage to the DVR required for compensating the long time and depth voltage disturbances in the distribution network [11]. The proposed technique involves the integration of DVR with battery bank supplied by the PV system. This approach has the advantage of supplying a reasonable amount of energy required by the DVR for compensating the complex voltage disturbance in distribution network. The fundamental working of DVR is to inject a voltage at a particular amount of magnitude, frequency and phase angle in series and synchronously with the distribution feeder required to preserve the desired waveform and amplitude of load voltage especially during the occurrence of voltage unbalance or distortion supplied from the main grid or point common coupling (PCC) [12]. Figure 2 shows a schematic diagram of DVR that operates by receiving the complex voltage disturbance signal from the main grid or PCC at point E and is compared with the reference voltage in DVR controller at point G. Then, the difference signal is used by the hysteresis switching relays to generate the unipolar SPWM signal required by the IGBT switches at point F. The energy bank that supply a DC voltage via DC link will convert into AC supply voltage by the IGBT switches and inject into the distribution network through the three-phase isolation transformer at point $\mathrm{D}$ for compensating the complex voltage disturbance [13].

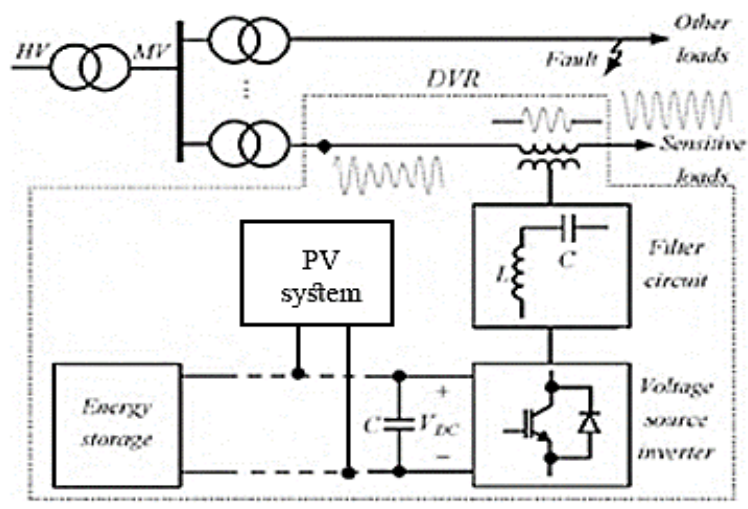

Figure 1. Proposed technique of DVR integrated with battery bank and PV system. 


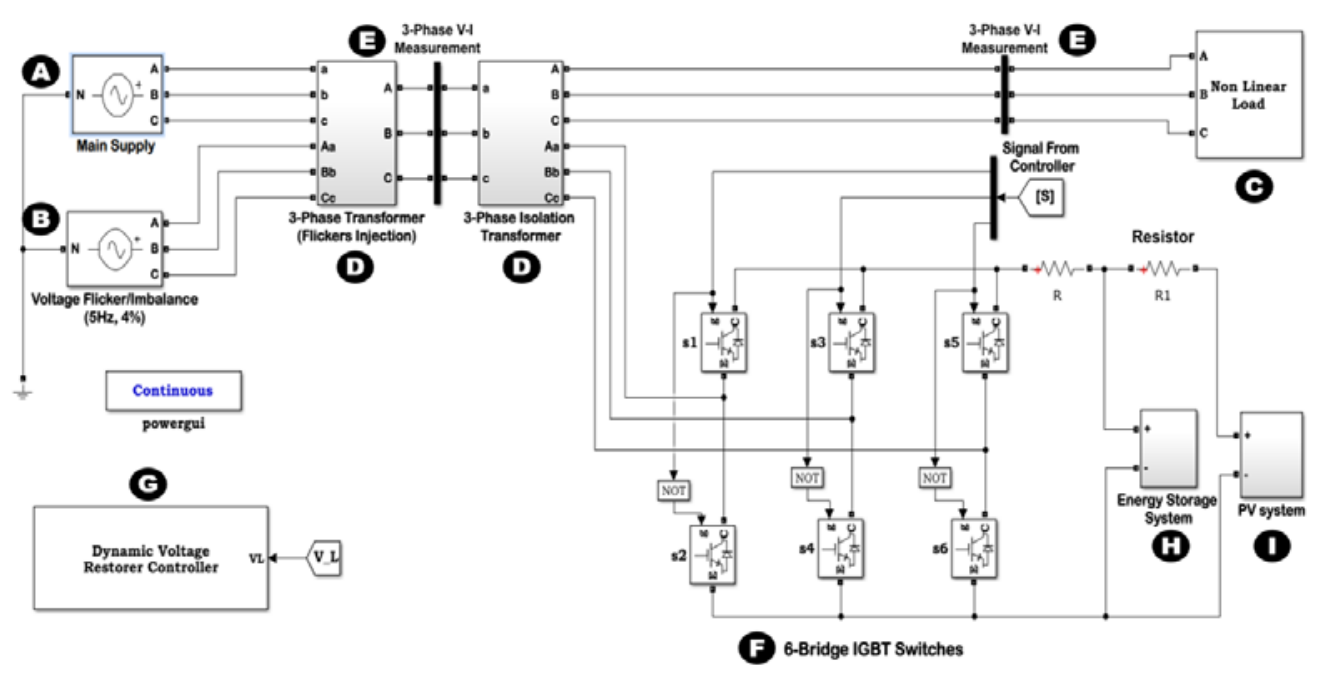

Figure 2. Schematic diagram of DVR integrated with the battery bank and PV system for complex voltage disturbance compensation.

\subsection{Three-Phase Programmable Voltage Source}

In Figure 2, the three-phase programmable voltage source representing as the main grid or PCC was set with the positive-sequence voltage of $508 \mathrm{~V}_{\mathrm{L}-\mathrm{L}}$ with $0^{\circ}$ phase angle at $50 \mathrm{~Hz}$ to supply the fundamental rms voltage of $415 \mathrm{~V}_{\mathrm{L}-\mathrm{L}}$ at point $\mathrm{A}$. The three-phase programmable voltage source is specified to generate a complex voltage disturbance of voltage sag or undervoltage at $70 \%$ from the fundamental rms voltage supply within a certain duration specifically designed for the case study 2 which will be discussed in the ensuing section. In the case study 3 , the three-phase programmable voltage source will generate a complex voltage disturbance of voltage swell or overvoltage at $170 \%$ from the fundamental rms voltage supply within a certain duration $[14,15]$. The effect of harmonic in the fundamental rms voltage supply will be generated from the main grid or PCC for case study 1.

\subsection{Three-Phase Voltage flicker/Imbalance Programmable Source}

The external voltage source is used to inject the voltage flickers through the three-phase isolation transformer that flows into the distribution network at point B in Figure 2. This will be the case study 4 having the injected external voltage source consisting with $20.32 \mathrm{~V}_{\mathrm{L}-\mathrm{L}}$ of positive-sequence voltage that is $4 \%$ from the fundamental rms voltage supply including $0^{\circ}$ phase angle at $5 \mathrm{~Hz}[16]$.

\subsubsection{Non-Linear Load}

The non-linear load is used in the case studies whereby the impedance is changing corresponding to the variation of the voltage. Therefore, the current produced will not be sinusoidal even if it is connected to a sinusoidal voltage because of connected by the non-linear load [17]. These non-sinusoidal currents will carry harmonic currents that interact with the impedance of distribution network to produce voltage interruptions which may influence both the connected load and the equipment [18].

\subsubsection{DVR Controller}

The main function of DVR is also to protect the sensitive load against a complex voltage disturbance at PCC bus in which the voltage is supplied from the distribution network. The DVR controller circuit received the signals from the source with distorted input supply, $V_{s}$, and load voltage of sensitive load. Prior to the comparison, the distorted supply voltages coming from the main grid or PCC are measured and multiplied by the gain, $k$, derived from the peak amplitude of fundamental input voltage, $V_{m}$, originated from the $V_{L-L}$ to change in per unit value of voltage [19]. Then, a sinusoidal unit vector, $\omega t$, is generated by using the sinusoidal function by using a three phase locked loop (PLL)[20]. The reference load voltage, Vref, signal is derived by considering the $\omega t$ as gains in $(1,2,3)$.

$$
\begin{aligned}
& V_{\text {ref } A}=V_{L L} \sin (\omega t+\varphi) \\
& V_{\text {ref } B}=V_{L L} \sin (\omega t+\varphi-2 \pi / 3)
\end{aligned}
$$




$$
V_{\text {refC }}=V_{L L} \sin (\omega t+\varphi+2 \pi / 3)
$$

Where, $V_{L-L}$ is the actual voltage magnitude of $415 \mathrm{~V}_{\mathrm{LL}}$.and $\varphi$ is the phase angle shift $\left({ }^{\circ}\right)$. The load reference voltage of pulse width modulation (PWM) is obtained from the comparison between Vref and load voltage of $V_{\text {Load. }}$ Via the hysteresis voltage control [21]. Simultaneously, the load reference voltage of pulse width modulation (PWM) is used to trigger the operation of IGBT switches [22,23].

\subsubsection{Battery Bank}

In Figure 2, a battery bank at point $\mathrm{H}$ is connected in parallel with the $\mathrm{DC}$ link to restore the capacity shortage of the capacitor. In order to ensure that the DVR perform effectively, the DC link voltage should be greater than double the rated voltage of the distribution system. Hence, the preferable amount of DC link voltage is given by the following equation in (4).

$$
V_{d c}=\frac{2 \sqrt{2} V_{L L}}{\sqrt{3} m}
$$

Where, $m$ is the modulation index. Hence, the calculated value of $V_{d c}$ is $678 \mathrm{~V}$ for $m$ is 1 and $V_{L L}=$ $415 \mathrm{~V}$. In this study, the battery voltage is set to $700 \mathrm{~V}$.

\subsubsection{Photovoltaic System}

Figure 3(a) shows the equivalent circuit of a photovoltaic system. In the proposed technique, the photovoltaic system is link up in parallel with DC link for supplying energy as a source to the battery bank at point $\mathrm{I}$ in the Figure 2.

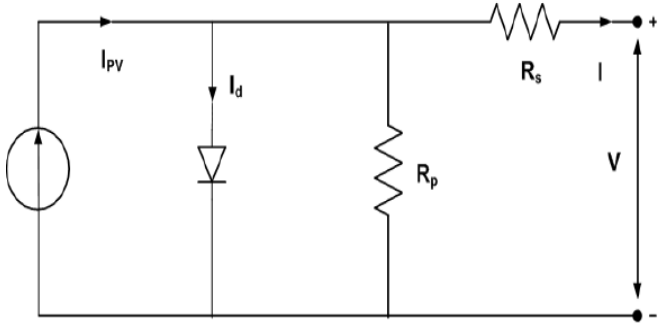

(a)

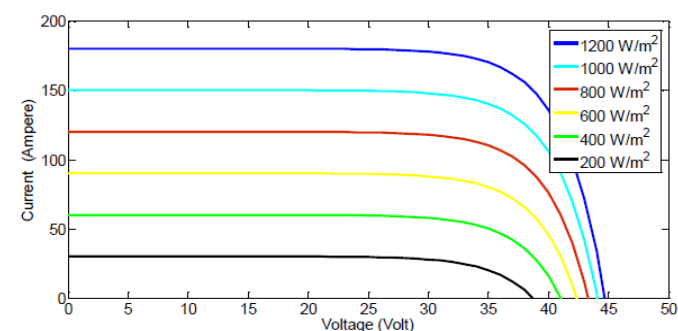

(b)

Figure 3. (a) Equivalent circuit of photovoltaic system and (b) V-I characteristic of photovoltaic system.

In Figure 3(b), shows the graph of the V-I characteristic of a photovoltaic system that depend on the irradiance of light. The equation of V-I characteristic of a photovoltaic system shown in (5).

$$
I=I_{P V}-I_{O}\left[\exp \left(\frac{V+R_{S} I}{\alpha V_{t}}\right)-1\right]-\frac{V+R_{S} I}{R_{P}}
$$

Where, $I_{P V}$ is the photovoltaic current, $I_{o}$ is saturated opposite current, $a$ is an ideal diode constant, $V_{t}=N_{S} K T q_{-1}$ is the thermal voltage, $N_{S}$ is the number of series cells, $q$ is the electron charge, $K$ is the Boltzmann constant, $T$ is the temperature of $\mathrm{p}-\mathrm{n}$ junction, and $R_{S}$ and $R_{P}$ are series and parallel equivalent resistance of the solar panels, respectively. $I_{P V}$ has a linear relation with light intensity and also varies with temperature variations [24]. $I_{o}$ is relying on temperature variations. The values of $I_{p v}$ and $I_{o}$ are calculated by using (6) and (7):

$$
\begin{aligned}
& I_{P V}=\left(I_{P V, n}+K_{1} \Delta T\right) \frac{G}{G_{n}} I \\
& I_{O}=\frac{I_{S C, n}+K_{1} \Delta T}{\exp \left(V_{O C, n}+K_{V} \Delta T\right) / \alpha V_{t}-1}
\end{aligned}
$$

In which $I_{P V, n}, I_{S C, n}$ and $V_{O C, n}$ are photovoltaic current, open circuit voltage and short circuit current in typical state ( $T_{n}=25 \mathrm{C}$ and $\left.G_{n}=1000 \mathrm{Wm}-2\right)$, respectively. $K_{I}$ is the coefficient of short circuit current to temperature, $\Delta T=T-T_{n}$ is the temperature divergence from typical temperature, $G$ is the light intensity and $K_{V}$ is the ratio coefficient of open circuit voltage to temperature. Short circuit current, open circuit voltage and 
voltage-current equivalent to the highest power are three important points of $\mathrm{I}-\mathrm{V}$ characteristic of photovoltaic system [25].

\section{SIMULATION RESULTS AND ANALYSIS}

The proposed circuit diagram of DVR employed for compensation of complex voltage disturbance is shown in Figure 2 and it has been simulated using Matlab/Simulink. The operation of DVR is performed based on different supply complex voltage disturbances and is tested under various operating state. DVR with the proposed controller scheme have been designed for the compensation of long and deep complex voltage disturbance under several case studies. DVR was used to stabilize the voltage of load demand connected at the PCC as the main grid supply containing a complex voltage disturbance caused by the fault that happened at the other side of load [26].

\subsection{Case Study 1: Voltage harmonic and flicker}

Figure 4(a) shows the unbalanced supply voltage waveform under nonlinear load condition at PCC caused by the harmonic injected from the source at PCC. The DVR compensates the unbalanced supply voltage condition caused by injected harmonic. Figure 4(c) shows the AC voltage injected into the distribution network for compensating the unbalanced voltage hence supplying a stable voltage to the load side as shown in Figure 4(b). On the other side, Figure 5(a) show the 4\% flickers of 5Hz from the desired output voltage within the duration of 0.05 second to 0.15 second at the PCC and this is specified based on the IEEE Standard 1159-1995. Figure 5(c) shows the AC voltage injected by the DVR into the distribution network for compensating the unbalanced voltage flickers and supplying a stable voltage to the load as shown in Figure 5(b).
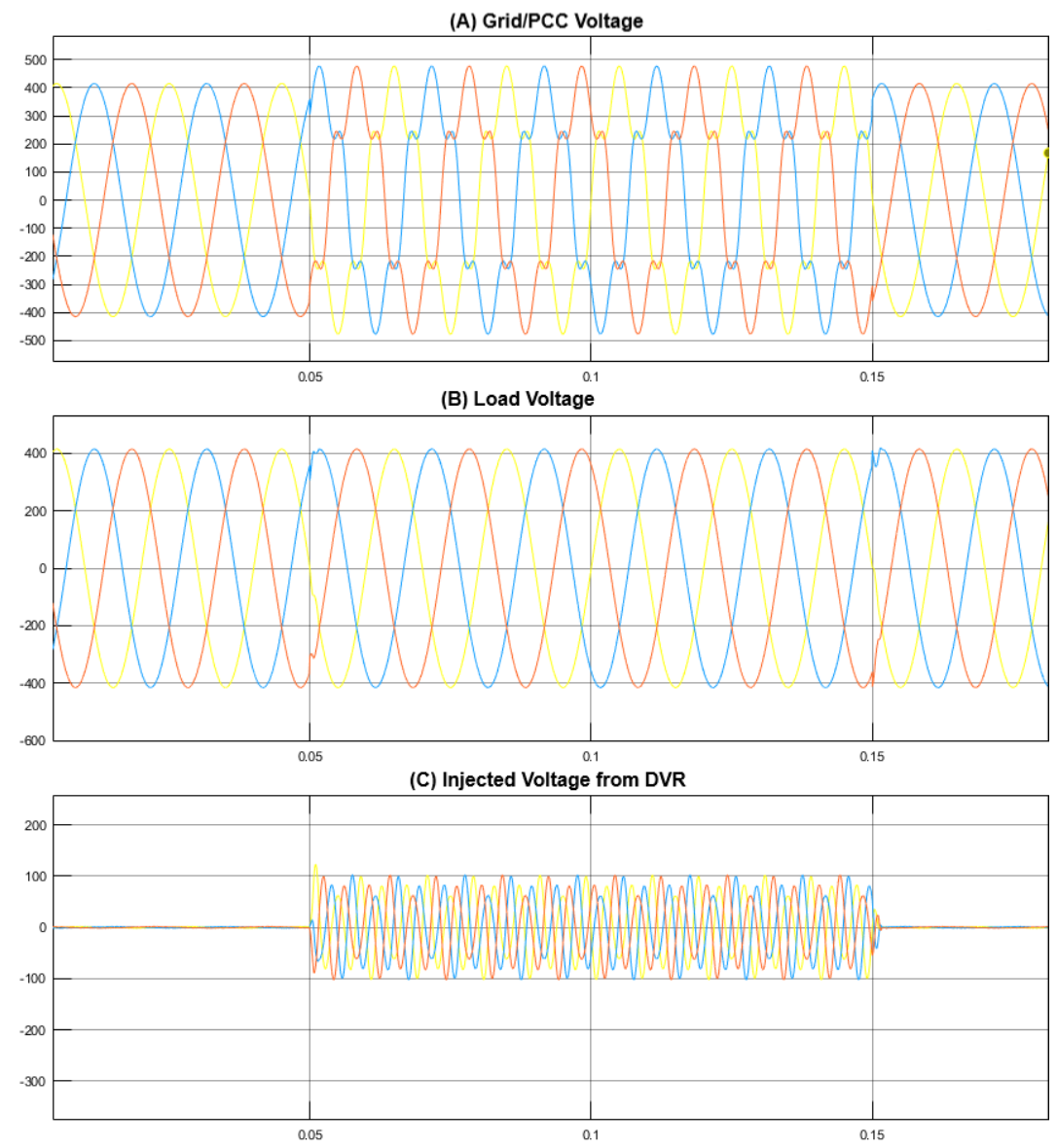

Int J Pow Elec \& Dri Syst Vol. 10, No. 4, Dec 2019 : 2222 - 2230 
Figure 4. DVR is compensating imbalance voltage cause by the harmonic (a) Voltage disturbance at PCC, (b) Voltage at the load after compensation, and (c) Voltage injected into the distribution network by DVR.
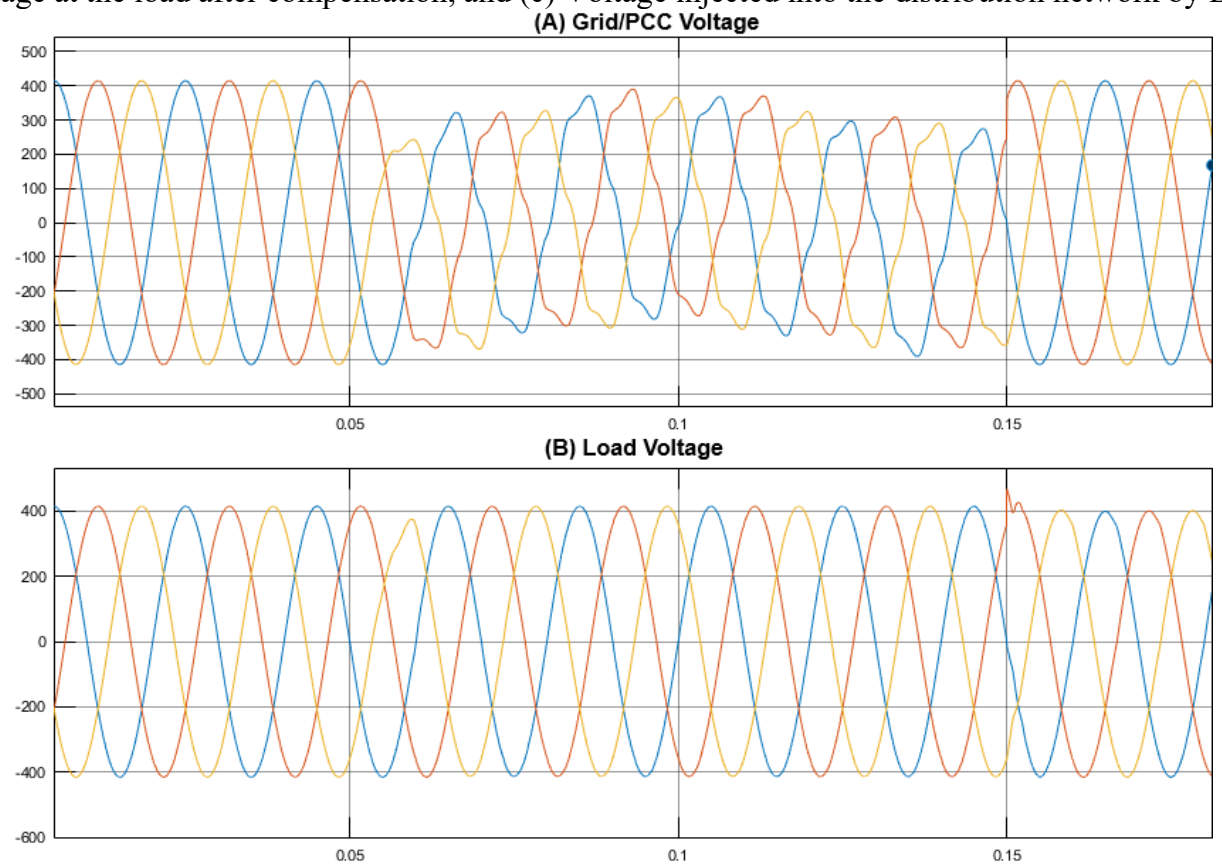

(C) Injected Voltage from DVR

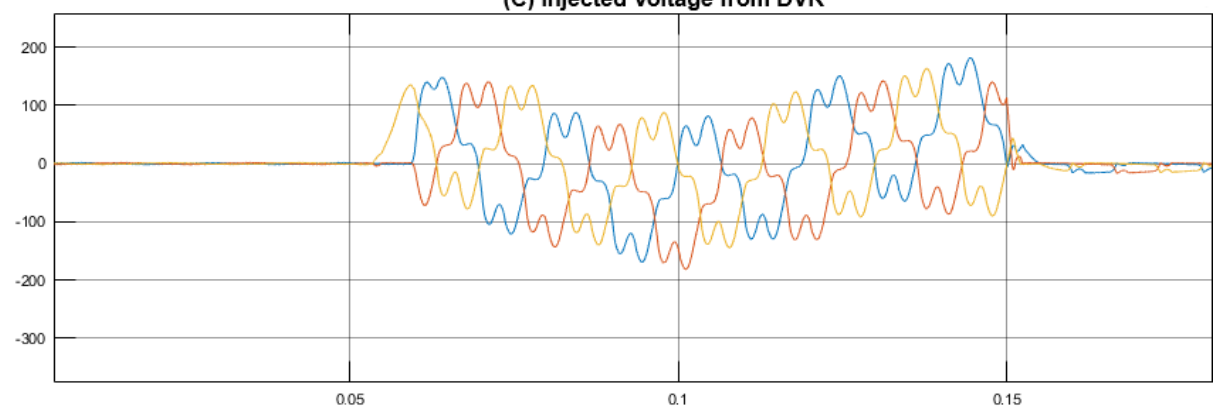

Figure 5. DVR is compensating 4\% of voltage flickers (a) Voltage disturbance at PCC, (b) Voltage at the load after compensation, and (c) Voltage injected into the distribution network by DVR.

\subsection{Case Study 2: Voltage Swell/Overvoltage}

The second case study involves compensation of voltage swell or overvoltage under nonlinear load condition. This problem occurs because of either the distribution network is lacking with the required voltage regulation, insufficient voltage control or temporary voltage rise during a single line-to-ground fault. Usually, the consequences happened due to the load switching such, capacitor bank operation or inaccurate tap setting of transformers. The $170 \%$ of voltage swell begins from 0.2 second until 3.2 second at PCC shown in Figure 6(a). The voltage swells or overvoltage is set based on the IEEE Standard 1159-1995. Thus, the DVR controller detect the 1.7 p.u. of voltage swell at PCC and compare it with the fixed reference voltage of 1.0 p.u. that eventually driven the IGBT switches to inject AC supply in negative magnitude to compensate the remaining magnitude of voltage swell shown in Figure 6(c). The improved incoming voltage for load subject to the compensation made by the DVR is shown in Figure 6(b). It is observed that the DVR immediately injects the remaining magnitude of voltage elements to preserve the load voltage. 


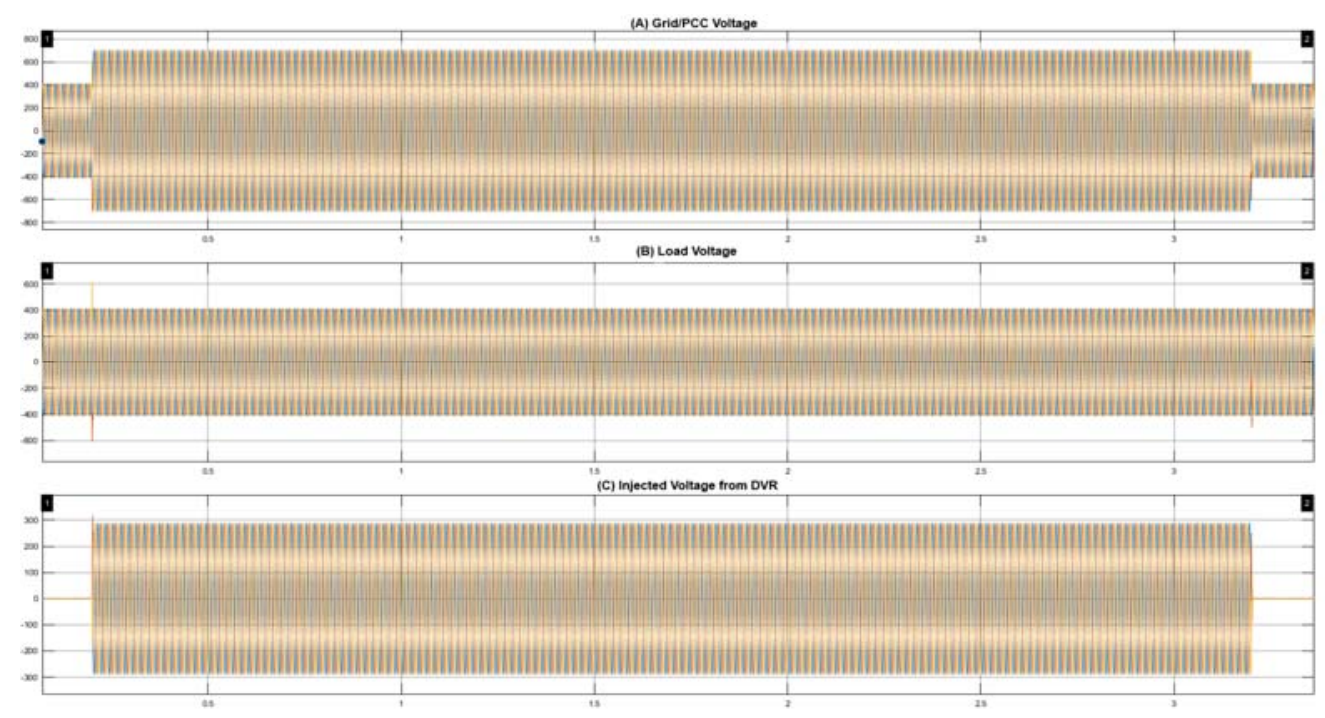

Figure 6. DVR is compensating $70 \%$ of Voltage Swell/Overvoltage (a) Voltage with disturbance at PCC, (b) Voltage at the load after compensation, and (c) Voltage injected into distribution network by DVR.

\subsection{Case Study 3: Complex voltage disturbance combination Voltage sag and flickers}

The third case study is compensation of complex voltage disturbance comprises a combination of voltage sag and flickers under nonlinear load condition. Voltage sag is created by either starting large motors, energization of heavy loads, or a single-line-to-ground fault in another feeder of the same substation. The problems usually happened until the voltage regulation appliances bring back the voltage within tolerances. Besides that, flickers is usually happened because of the distribution system is too week to support the load resulting to a low short-circuit ratio. Voltage variations that occur from flickering are often within the normal voltage range, but the change is fast enough to interrupt at end user. The $70 \%$ of voltage sag happened at 0.05 second until 0.65 second at PCC as shown in Figure 7. Hence, the three-phase supply voltage at PCC drops to 0.3 p.u. during the sag condition and it is specified based on the IEEE Standard 1159-1995. Furthermore, the $4 \%$ flickers at $5 \mathrm{~Hz}$ is applied based on the specification in IEEE Standard 1159-1995 combined with the voltage sag disturbance at duration 0.25 second to 0.45 second at PCC shown in Figure 7(a).

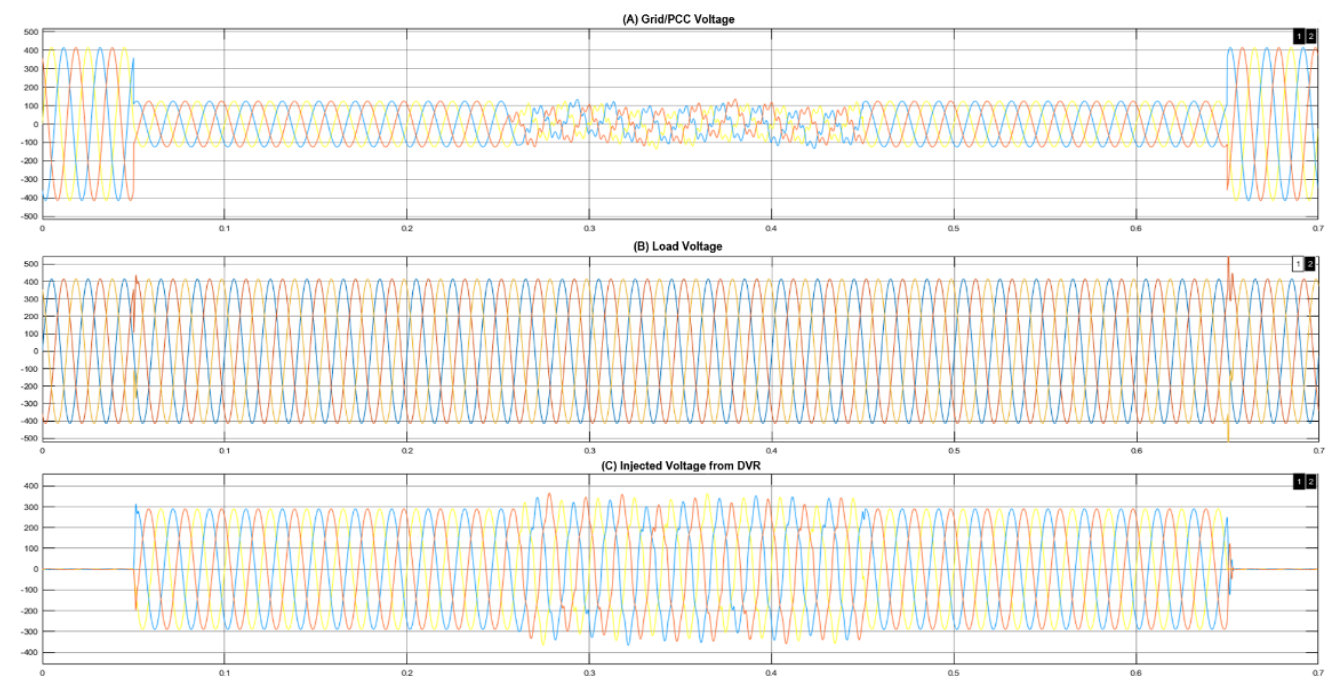

Figure 7. DVR is compensating complex power quality combination between $70 \%$ of Voltage Sag (a) Voltage sag with flickers, (b) Voltage at the load after compensation, and (c) Voltage injected into distribution network by DVR.

Int J Pow Elec \& Dri Syst Vol. 10, No. 4, Dec 2019 : 2222 - 2230 
Thus, the DVR controller detect the 0.3 p.u. of supply voltage sag combined with flickers at PCC and compared it with the fixed reference voltage of 1.0 p.u. at nominal voltage. Eventually, driven the IGBT switches to inject AC supply in positive magnitude to compensate 0.3 p.u. remaining magnitude of voltage sag and unbalance voltage flickers shown in Figure 7(c). The improved incoming voltage connected to the load subject to the compensation made by the DVR is shown in Figure 7(b). It is observed that to preserve the load voltage of sensitive load, the DVR immediately injects the necessary voltage elements.

\section{CONCLUSION}

This article discussed on the compensation technique of complex voltage disturbance as safeguarding the power quality by using DVR to preserve controllable voltage stability between the PCC and the distribution network. The proposed of DVR integrating with battery bank supplied by photovoltaic system at the DC link was introduced to supply enough energy to overcome long and deep complex voltage disturbance. Based on the simulation, the DVR is robust in solving the voltage sags and swell coming from the PCC and protecting the sensitive loads. The DVR overcome the complex voltage disturbance without any difficulties during balanced and unbalanced state considering harmonic and flicker. In order to maintain the load voltage balanced at the nominal value, the DVR inject the appropriate voltage component to improvise rapidly any disturbance in the supply voltage. The DVR integrating with battery bank supplied by photovoltaic system is a competent solution due to its compact size, relatively low cost, and quick-dynamic response for compensation the complex voltage disturbance.

\section{ACKNOWLEDGEMENTS}

This research was supported by the Long-Term Research Grant (LRGS), Ministry of Education Malaysia for the program titled "Decarbonisation of Grid with an Optimal Controller and Energy Management for Energy Storage System in Microgrid Applications" with project code 600-IRMI/LRGS 5/3 (001/2019). The authors would also like to acknowledge The Institute of Research Management \& Innovation (IRMI), Universiti Teknologi MARA (UiTM), Shah Alam, Selangor, Malaysia for the facilities provided to support on this research.

\section{REFERENCES}

[1] H. W. B. Roger C. Dugan, "Mark F. McGranaghan, Surya Santoso, Electrical Power Systems Quality," Second Edition, Second. McGraw-Hill Professional, 2002.

[2] V. Khadkikar, "Enhancing Electric Power Quality Using UPQC : A Comprehensive Overview," IEEE Trans. Power Electron, vol. 27, no. 5, pp. 2284-2297, 2012.

[3] C. R. Bayliss and B. J. Hardy, "Power Quality - Voltage Disturbances," Transm. Distrib. Electr. Eng., pp. 10131026, 2011.

[4] D. De Yong, S. Bhowmik, and F. Magnago, "Optimized Complex Power Quality Classifier Using One vs. Rest Support Vector Machines," Energy Power Eng., vol. 09, no. 10, pp. 568-587, 2017.

[5] R. Saini, O. P. Mahela, and D. Sharma, "Detection and Classification of Complex Power Quality Disturbances Using Hilbert Transform and Rule Based Decision Tree," 8th IEEE Power India Int. Conf. PIICON 2018, no. v, 2019.

[6] S. A. Zegnoun, M. N. Tandjaoui, M. Djebbar, C. Benachaiba, and B. Mazari, "Power quality enhancement by using D-FACTS systems applied to distributed generation," Int. J. Power Electron. Drive Syst., vol. 10, no. 1, pp. 330341, 2019

[7] E. Babaei, M. F. Kangarlu, and M. Sabahi, "Compensation of voltage disturbances in distribution systems using single-phase dynamic voltage restorer," Electr. Power Syst. Res., vol. 80, no. 12, pp. 1413-1420, 2010.

[8] M. T. L. Gayatri, A. M. Parimi, and A. V. Pavan Kumar, "A review of reactive power compensation techniques in microgrids," Renew. Sustain. Energy Rev., vol. 81, no. January, pp. 1030-1036, 2018.

[9] S. Priyavarthini, C. Nagamani, G. S. Ilango, and M. A. A. Rani, "An improved control for simultaneous sag/swell mitigation and reactive power support in a grid-connected wind farm with DVR," Int. J. Electr. Power Energy Syst., vol. 101, no. September 2017, pp. 38-49, 2018.

[10] S. Devassy and B. Singh, "Design and Performance Analysis of Three-Phase Solar PV Integrated UPQC," IEEE Trans. Ind. Appl., vol. 54, no. 1, pp. 73-81, 2018.

[11] J. Ye, H. B. Gooi, B. Wang, Y. Li, and Y. Liu, "Elliptical restoration based single-phase dynamic voltage restorer for source power factor correction," Electr. Power Syst. Res., vol. 166, no. September 2018, pp. 199-209, 2019.

[12] M. I. Marei, A. B. Eltantawy, and A. A. El-Sattar, "An energy optimized control scheme for a transformerless DVR," Electr. Power Syst. Res., vol. 83, no. 1, pp. 110-118, 2012.

[13] W. Chankhamrian and K. Bhumkittipich, "The effect of series-connected transformer in DVR applications," Energy Procedia, vol. 9, pp. 306-315, 2011.

[14] M. M. Othman, N. Muhamad, L. Fahmi, N. Rakami, and Z. Abdul, "Energy efficiency enhancement using dynamic voltage restorer ( DVR )," Int. J. Power Electron. Drive Syst., vol. 10, no. 3, pp. 1308-1316, 2019.

Dynamic voltage restorer (DVR) in a complex voltage disturbance compensation Muhammad Alif Mansor 
[15] H. Abdollahzadeh, M. Jazaeri, and A. Tavighi, "A new fast-converged estimation approach for Dynamic Voltage Restorer (DVR) to compensate voltage sags in waveform distortion conditions," Int. J. Electr. Power Energy Syst., vol. 54, pp. 598-609, 2014.

[16] H. Fujita and H. Akagi, "The unified power quality conditioner: The integration of series- and shunt-active filters," IEEE Trans. Power Electron., vol. 13, no. 2, pp. 315-322, 1998.

[17] K. Al Hosani, T. H. Nguyen, and N. Al Sayari, "An improved control strategy of 3P4W DVR systems under unbalanced and distorted voltage conditions," Int. J. Electr. Power Energy Syst., vol. 98, no. February 2017, pp. 233-242, 2018.

[18] R. Aboelsaud, A. Ibrahim, and A. G. Garganeev, "Review of three-phase inverters control for unbalanced load compensation," Int. J. Power Electron. Drive Syst., vol. 10, no. 1, pp. 242-255, 2019.

[19] [N. S. Rao, A. S. M. Selwin Mich Priyadharson, and J. Praveen, "Simulation of artificial intelligent controller based DVR for power quality improvement," Procedia Comput. Sci., vol. 47, no. C, pp. 153-167, 2014.

[20] M. Kesler and E. Ozdemir, "Synchronous-reference-frame-based control method for UPQC under unbalanced and distorted load conditions," IEEE Trans. Ind. Electron., vol. 58, no. 9, pp. 3967-3975, 2011.

[21] Teke, L. Saribulut, and M. Tumay, "A novel reference signal generation method for power-quality improvement of unified power-quality conditioner," IEEE Trans. Power Deliv., vol. 26, no. 4, pp. 2205-2214, 2011.

[22] M. I. Mosaad, M. O. Abed El-Raouf, M. A. Al-Ahmar, and F. M. Bendary, "Optimal PI controller of DVR to enhance the performance of hybrid power system feeding a remote area in Egypt," Sustain. Cities Soc., vol. 47, p. $101469,2019$.

[23] S. A. Taher, H. T. Fard, and E. B. Kashani, "New switching approach for DVR using one cycle control method," Ain Shams Eng. J., vol. 9, no. 4, pp. 2227-2254, 2018.

[24] O. Penangsang and A. Soeprijanto, "Matlab / simulink simulation of unified power quality conditioner-battery energy storage system supplied by PV-wind hybrid using fuzzy logic controller," vol. 9, no. 3, pp. 1479-1495, 2019.

[25] M. Prasad and A. K. Akella, "Voltage and Current Quality Improvement by Solar Photovoltaic fed ZSI-DVR," Procedia Comput. Sci., vol. 125, pp. 434-441, 2018.

[26] M. T. Hagh, A. Shaker, F. Sohrabi, and I. S. Gunsel, "Fuzzy-based controller for DVR in the presence of DG," Procedia Comput. Sci., vol. 120, pp. 684-690, 2017.

Int J Pow Elec \& Dri Syst Vol. 10, No. 4, Dec 2019 : 2222 - 2230 